\title{
Jueces y Derechos Humanos Hacia un Sistema Judicial Transnacional
}

Sergio S. Aguirre Anguiano

¿Es posible hablar de un Sistema Transnacional de Protección Judicial de los Derechos Humanos conformado tanto por tribunales nacionales como internacionales?

Mara

Gómez, autora del libro Jueces y Derechos Humanos publicado por la casa editorial Porrúa, sostiene que sí.

En esta obra, que recientemente fue presentada en la Escuela Libre de Derecho y en la Suprema Corte de Justicia de la Nación, se afirma que en nuestros días los tribunales del mundo están tendiendo a conformar una red, un sistema de órganos jurisdiccionales que, como si se tratara de la sinapsis de neuronas, van conectándose para configurar una estructura destinada a convertirse en un arma poderosa para la protección de los derechos humanos en todo el mundo.

La autora sostiene que son

pocos quienes se han percatado de la enorme expansión que ha sufrido la justicia tanto nacional como internacional, después de la Segunda Guerra Mundial, y dice también que no sólo ha aumentado el número de tribunales en el mundo, sino que ahora, también su alcance e influencia son mucho mayores.

Este aumento en el número e importancia de los tribunales a nivel mundial ha tenido efectos muy importantes en cuanto a su forma de trabajo, pero sobre todo, en cuanto a los vínculos, nexos y contactos que ahora se dan entre ellos, lo que a juicio de Mara Gómez, está tendiendo a conformar una comunidad judicial y una cultura común entre los jueces del mundo

Los tribunales nacionales e internacionales se están comunicando cada día más y con más frecuencia; los tribunales internacionales están encontrando cada vez más nexos y puntos de contacto entre sí, y los tribunales nacionales de los diversos países 
se están vinculando unos con otros cada vez más.

En la actualidad, los tribunales domésticos aplican muchas más normas internacionales que hace unas cuantas décadas, y son cada vez más los casos en que los tribunales nacionales tienen que acudir a tratados internacionales para la resolución de un caso, o en los que deciden, por iniciativa propia, consultar los precedentes de una corte de otro país, o incluso la jurisprudencia internacional. Y esto sucede de manera muy especial cuando se trata de la resolución de casos sobre derechos humanos.

A la par, los tribunales internacionales han modificado sustancialmente su forma de operar y están actuando cada vez más como tribunales nacionales; esto es, están condenado a personas por la comisión de crímenes y enviándolas a prisión, tal cual lo hacen los tribunales penales nacionales; están ejerciendo jurisdicción sobre litigios comerciales, casi como si fuesen juzgados mercantiles, y están anulando leyes nacionales, cual lo hacen los tribunales constitucionales.

Pero la interacción de los tribunales abarca todavía más aspectos. La semejanza en las funciones judiciales y la coincidencia de intereses ha generado que los juzgadores busquen la forma de conocerse, de reunirse, de conversar y eventualmente, de conformar organizaciones que los agrupen. De hecho, al día de hoy existen en el mundo una gran cantidad de asociaciones internacionales que congregan a tribunales.

Es por ello que, desde la perspectiva de Mara Gómez, cada vez es mayor la internacionalización de lo nacional y la nacionalización de lo internacional, y progresivamente, van aumentando las conexiones entre los tribunales de todo el mundo.

En ese sentido, dice la Dra. Gómez, la incesante y cada vez mayor interacción entre los tribunales del mundo es lo que está dando lugar a un sistema judicial transnacional de tribunales, integrado tanto por órganos nacionales, como por órganos internacionales.

Son los propios jueces, dice Gómez Pérez, quienes se están reuniendo cada vez más, quienes se están leyendo mutuamente y cada vez con más frecuencia y, sobre todo, quienes se están citando cada vez más unos a otros. En esa medida, si bien tanto los jueces nacionales como los internacionales siguien siendo competentes en una jurisdicción específica que está basada en un conjunto particular de leyes, al mismo tiempo son cada vez más, elementos de un sistema, 
de un sistema transnacional.

Pero más allá de todas estas revolucionarias e inquietantes ideas, el libro de Mara Gómez constituye un compendio útil y bien documentado sobre la función central que desempeñan los tribunales nacionales e internacionales en la protección y defensa de los derechos humanos.

La Corte Internacional de Justicia, los Tribunales Internacionales para Ruanda y la ex Yugoslavia, la Corte Penal Internacional, el Tribunal Europeo y la Corte Interamericana de Derechos Humanos; el Caso "Avena", el Caso Rosendo Radilla, los célebres juicios contra Pinochet, Cavallo y Eichmann; la Teoría del Bloque de Constitucionalidad y el Control de Convencionalidad, así como la Innovadora Justicia Transicional, son sólo algunos de los procesos, teorías y tribunales que, para conocimiento del lector, son explicados detalladamente en este libro.

Esta obra, que ya está de nuevo a la venta después de que se agotó rápidamente la primera edición, vale mucho la pena ser leída por todos aquellos interesados en el importante rol que hoy día juegan los jueces del todo mundo en la protección y defensa de los derechos humanos.

Jueces y Derechos Humanos. Hacia un sistema judicial transnacional

Instituto Mexicano de Derecho Procesal Constitucional; Programa Universitario de Derechos Humanos de la UNAM; Editorial Porrúa Biblioteca Porrúa de Derecho Procesal Constitucional

México 2014

Autor: Gómez Pérez, Mara 


$$
\bar{x}
$$

